\title{
La violencia en Himmelweg de Juan Mayorga
}

\section{Manuel Aznar Soler}

\section{OpenEdition}

\section{Journals}

Edición electrónica

URL: https://journals.openedition.org/cher/1598

DOI: $10.4000 /$ cher.1598

ISSN: 2803-5992

\section{Editor}

Presses universitaires de Strasbourg

\section{Edición impresa}

Fecha de publicación: 1 diciembre 2017

Paginación: 79-98

ISBN: 978-2-86820-962-7

ISSN: 1968-035X

\section{Referencia electrónica}

Manuel Aznar Soler, «La violencia en Himmelweg de Juan Mayorga», reCHERches [En línea], 19 | 2017, Publicado el 01 diciembre 2021, consultado el 02 febrero 2022. URL: http://journals.openedition.org/ cher/1598; DOI: https://doi.org/10.4000/cher.1598

\section{c) (i) (2)}

Ce(tte) œuvre est mise à disposition selon les termes de la Licence Creative Commons Attribution Pas d'Utilisation Commerciale - Partage dans les Mêmes Conditions 4.0 International. 


\title{
La violencia en Himmelweg de Juan Mayorga
}

\author{
Manuel Aznar Soler'
}

$\mathrm{E}$ lema de la violencia está muy presente en la mayoría de las obras dramáticas de Juan Mayorga. En Himmelweg podríamos decir que esa violencia es estructural, es decir, que se trata de una violencia de situación, de una situación de violencia extrema. O, dicho de otra manera, que la violencia constituye el esqueleto dramatúrgico de la obra. El propio Mayorga, en una entrevista concedida a John P. Gabriele en el año 2000, es decir, tres años antes del estreno madrileño de Himmelweg, declaraba:

Yo creo que hay un tema que vertebra mi obra. Es la indagación acerca de la violencia. La violencia es un tema que me preocupa mucho y que está en alguna medida en todos mis textos. Entiendo por violencia la dominación de uno sobre otro o de una realidad sobre un ser humano, sea hombre o mujer. Me interesa poco la violencia explícita, o sea, física. Esa no creo que merezca la pena ser presentada en escena porque es evidente, es obvia. El teatro, el arte en general, no ha de presentar lo evidente, ha de intentar desvelar, revelar. Me interesan otras formas de violencia que están en la vida cotidiana, que están permanentemente, por decirlo de algún modo, violando el mandato de «No matarás». [...] Por eso me siento cerca de autores como Kafka o como Canetti, que son escritores que han tenido un especial olfato para detectar la violencia, para descubrir que la violencia está rodeándonos. La violencia es el gran mal. La violencia es intentar matar a otro, pero no a través de la muerte física sino a través de algo que puede ser mucho más perverso, que es la muerte moral, la humillación, la aniquilación moral de algún ser humano. (Gabriele 2009: 178-179)

En efecto, la relación dramática entre nazis y judíos en un imaginario campo de exterminio inspirado en el histórico de Theresienstadt (AAVV 1968), la relación entre un Comandante nazi apasionado del teatro y un coro de judíos encabezado por Gottfried, auténtico coro trágico de cadáveres vivos, es en Himmelweg una relación de extrema violencia: una relación, literalmente, a vida

1 Catedrático de literatura española contemporánea de la Universitat Autònoma de Barcelona, es fundador y director desde 1993 del Grupo de Estudios del Exilio Literario (GEXEL). 
o muerte. Unos judíos que, bajo la amenaza real de ser enviados a la cámara de gas, están obligados a actuar en una puesta en escena con el objetivo siniestro de dar gato por liebre al espectador, es decir, farsa nazi por tragedia judía. Y en este caso ante un único espectador, ante el Delegado de la Cruz Roja, que viene a ser una «especie de "metaespectador, para llamarlo de algún modo"» (Bartolomé 2011: 93).

Y si en «Teatro y verdad» Mayorga sostiene que el teatro debe servir para revelar la verdad (2011c: 188-190), en Himmelweg la función de esa puesta en escena, dirigida por un Comandante nazi, sirve justamente para lo contrario, para engañar al Delegado, En rigor, así sucedió en la realidad histórica cuando Maurice Rossel, delegado en Berlín del Comité de la Cruz Roja, visitó el 23 de junio de 1944 el campo de Theresienstadt (Aznar Soler 2011a: 24-29). Recordemos que este campo se creó como «un gueto especial para algunas categorías privilegiadas de judíos» (Arendt 2015: 120) con el propósito de ser «un escaparate para el mundo exterior -fue el único gueto o campo en el que se admitieron representantes de la Cruz Roja Internacional» (Arendt 2015: 122). Pues bien, en Himmelweg el teatro sirve para enmascarar la realidad trágica, la relación de extrema violencia entre el Comandante, Gottfried y demás judíos del campo, una relación, en palabras de Hannah Arendt, de «dominación total» (2006: 589). Una puesta en escena que se representa ante el Delegado, quien, tras contemplar el espectáculo, víctima del engaño a los ojos y de su propia cobardía, acabará por emitir un informe favorable a los nazis.

\section{Teatro y Shoah}

Michael Hofmann afirma en la introducción a su Historia de la literatura de la Shoah que «el acontecimiento fundamental de la Segunda Guerra Mundial fue el genocidio perpetrado a los judíos europeos en proporciones industriales: el "Holocausto", la "Shoah"» (2011: 5). Hofmann parte de la convicción de que «ha tenido lugar un "rompimiento civilizatorio" (Dan Diner), una incisión a través de la cual todos y cada uno de los fundamentos de la civilización occidental y de la humanidad han sido puestos en tela de juicio» (2011: 5). Reyes Mate (2003a, 2003b y 2006), director de un grupo de investigación en torno al tema en el Consejo Superior de Investigaciones Científicas de Madrid del que Juan Mayorga ha sido miembro durante unos años, así como Enzo Traverso (2001 y 2002), son autores de libros excelentes en donde han analizado con rigor la realidad de los campos de exterminio nazis y los problemas filosóficos, éticos y políticos que implican para los intelectuales y ciudadanos.

Obviamente, ese «rompimiento civilizatorio implica un rompimiento con todas las formas literarias tradicionales» (Hofmann 2011: 8), es decir, ese «rompimiento civilizatorio» ha intensificado «el proceso de transformación propio de los géneros y las formas literarias» (Hofmann 2011: 23). Por ello se propone «mostrar, a través del análisis de obras ejemplares, cómo es que las autoras y los autores logran trasladar a los textos literarios la conciencia del 
rompimiento civilizatorio» (2011: 23). Así, Hofmann, para quien «en la historia de la literatura de la Shoah el teatro ocupa un lugar de gran importancia» (2011: 109), analiza únicamente dos obras: La indagación, de Peter Weiss (1965) y Los caníbales, de George Tabori (1968). Sin embargo, está claro que, en este sentido, Himmelweg constituye también una obra «ejemplar», otro perfecto ejemplo de «rompimiento teatral». Una obra de Juan Mayorga a la que José Luis García Barrientos ha calificado como «su obra maestra hasta el momento» (2011: 39) y a la que, por mi parte, he valorado también «como una de las obras maestras, como sin duda uno de los mejores textos de literatura dramática escritos por un autor español durante esta primera década de nuestro siglo XXI» (Aznar Soler 2011a: 43).

\section{Dominación total y Todo es posible}

Hannah Arendt, en su ensayo «Sobre la violencia», afirma sobre el siglo xx "que ha resultado ser, como Lenin predijo, un siglo de guerras y revoluciones» (2005: 9). Y añade que «la ecuación de la violencia con el poder se basa en la concepción del Gobierno como dominio de un hombre sobre otros hombres por medio de la violencia» (2005: 72). Un dominio que únicamente será un «dominio total» en el caso de los totalitarismos, nazi o soviético. Y recordemos que Mayorga, como hemos visto, entiende por violencia «la dominación de uno sobre otro o de una realidad sobre un ser humano, sea hombre o mujer»; que le interesa "poco la violencia explícita, o sea, física» porque «es evidente, es obvia»; y que, en su ensayo sobre «La representación teatral del Holocausto», se declara absolutamente en contra de «la manipulación sentimental del sufrimiento, la exhibición obscena de la violencia, la explotación del siniestro glamour del Lager» (2011c: 195).

Invisibilidad de la violencia y del horror porque en Himmelweg, y a mi modo de ver es uno de los mayores aciertos dramatúrgicos de Mayorga, esa violencia no es una "violencia física explícita», aunque no por ello esa violencia es menos evidente, sutil, cínica, dura, inhumana y cruel, tal y como declara el propio autor en una entrevista que publiqué en mi edición de la obra:

No hay ningún momento de Himmelweg en que aparezca violencia física explícita. Tal cosa sería ingenua y engañosa: nada que pongamos en escena podría representar el horror de la cámara de gas. Sin embargo, Himmelweg es una obra atravesada por la violencia. Que la relación entre Gottfried y el Comandante a veces parezca casi amistosa, o que los judíos forzados a interpretar la felicidad a ratos parezcan sentirla, eso es extraordinariamente violento, porque sabemos que debajo de esa amistad y de esa felicidad aparentes hay una amenaza de muerte. (Aznar Soler 2011b: 270)

En efecto, el Comandante nazi ejerce una «dominación total» sobre Gottfried y el coro de judíos, sostiene un permanente pulso a lo largo de toda la obra en el que el verdugo somete a las víctimas a todo tipo de violencias: desde obligarles «a defender el relato de los verdugos» (Mayorga 2011c: 45) a la situación de 
extrema violencia que padece Gotfried al tener que elegir entre únicamente cien actores en la escena de la plaza, reducción que implica la muerte para los judíos «excedentes»; o entre la servidumbre de colaborar forzosamente en su función de «traductor» a la crueldad del Comandante cuando realiza la reflexión metateatral final, titulada «la melancolía del actor», verdadera sentencia de muerte tanto para Gottfried como para todos los demás judíos que han intervenido en la representación.

Hannah Arendt, en la tercera parte de su libro Los orígenes del totalitarismo, dedica el epígrafe tercero («Dominación total») del capítulo 12 («El totalitarismo en el poder») al análisis de los campos de concentración y de exterminio nazis, así como los del gulag soviético y afirma que «los campos de concentración y exterminio de los regímenes totalitarios sirven de laboratorios en los que se pone a prueba la creencia fundamental del totalitarismo de que todo es posible» (Arendt 2006: 589).

Y dentro de ese «todo es posible» cabe la relación de extrema violencia, a vida o muerte, esa relación de «dominación total» (Arendt 2006: 589) que nos plantea Mayorga en Himmelweg entre el Comandante nazi y Gottfried, el falso Alcalde judío del campo de exterminio. Contrariamente a la convicción de que «la idea de dominación total era no sólo inhumana, sino también irreal» (Arendt 2006: 612), con la historia del nazismo «hemos aprendido que el poder del hombre es tan grande que realmente puede ser lo que quiera ser» (Arendt 2006: 612). Porque, al igual que el bombardeo de Guernica durante la guerra civil española por la Legión Cóndor de la Alemania nazi, el ficticio campo de Himmelweg no es sino un «laboratorio» donde va a experimentarse una puesta en escena de «dominación total»:

Los campos son concebidos no sólo para exterminar a las personas y degradar a los seres humanos, sino también para servir a los terribles experimentos de eliminar, bajo condiciones científicamente controladas, la misma espontaneidad como expresión del comportamiento humano y de transformar la personalidad humana en una simple cosa, en algo que ni siquiera son los animales; porque el perro de Pavlov que, como sabemos, había sido preparado para comer no cuando tuviera hambre, sino cuando sonara una campana, era un animal pervertido. [...] Sólo en los campos de concentración es posible semejante experimento [...] El experimento de dominación total en los campos de concentración depende del aislamiento respecto del mundo de todos los demás, del mundo de los vivos en general. (Arendt 2006: 590)

Así pues, en Himmelweg el campo se convierte en un «laboratorio» teatral en el que debe representarse una puesta en escena de una obra compuesta por el Comandante nazi con la ayuda del judío Gottfried, un individuo «inocente» en el lenguaje de Arendt. Una función ante un único espectador, el Delegado, que representa a la humanidad.

Y si el campo es un Infierno, en la representación debe parecer el Paraíso. Por ello Wilfried Floeck afirma que "Himmelweg es una especie de "Gran teatro del mundo", en el que, sin embargo, el director no es Dios, sino el diablo en 
la persona del Comandante nazi»(Floeck 2012), mientras que, por su parte, Arendt afirma que:

[...] el Infierno y el Purgatorio, e incluso una sombra de su duración perpetua, pueden lograrse mediante los más modernos métodos de destrucción y terapia. Para estas personas (que en cualquier gran ciudad son más numerosas de lo que nos gustaría reconocer), el infierno totalitario demuestra sólo que el poder del hombre es más grande de lo que se habían atrevido a pensar y que el hombre puede hacer realidad diabólicas fantasías sin que el cielo se caiga o la tierra se abra. (Arendt 2006: 599-600)

\section{Unos judíos «elegidos»}

El Comandante de Himmelweg dice haber recibido poco antes de las seis de la mañana, la hora en que, con puntualidad prusiana, llegan diariamente los trenes al campo, un telegrama de Berlín en donde se le ordena ejecutar una puesta en escena teatral para la que necesita formar una compañía compuesta por judíos. Y estos judíos son Gottfried y sus compañeros, que ese día estaban a punto de llegar en uno de aquellos «trenes de la muerte» de trágica memoria. Y si hay ironía trágica del burlador burlado cuando escuchamos decir al Delegado en su monólogo inicial que «se trata de darle confianza, de hacer teatro» ante el Comandante $(133)^{2}$, también existe ironía trágica al referirse el Comandante nazi en su diálogo con Gottfried al privilegio de este grupo de judíos de haber sido «elegidos» para llevar a cabo una misión que, aunque les conducirá finalmente a la muerte, les ha salvado momentáneamente la vida, aunque no les va a ahorrar una lenta agonía en forma de ensayos reiterados hasta la representación final: «Esto es una experiencia modelo. Se les ha concedido un estatus especial. Berlín los ha elegido» (161). Así, si los judíos fueron el pueblo elegido por Dios, este grupo de judíos ha sido elegido por Berlín, por los jerarcas nazis, para interpretar una farsa que sirva a la propaganda hitleriana para negar como una mera fabulación de la propaganda antifascista y comunista la existencia de «hombres flacos con pijamas de rayas» (148) en sus campos: "También yo he oído esas fantasías. También usted las ha oído, ¿verdad, Gottfried?» (134). Una mentira más del Comandante cuya veracidad está obligado a confirmar el judío por la situación de violencia que padece: «Gottfried contesta que sí, que también él las ha oído» (134), nos dice en su monólogo el Delegado. Porque representar el teatro de la mentira y defender el relato del verdugo son las únicas maneras que tienen las víctimas de sobrevivir, tal y como le recuerda el Comandante: «Créame si le digo que, de no haber llegado a tiempo ese mensaje, usted y yo no estaríamos hablando en estos momentos. ¿Comprende lo que le estoy diciendo?» (169)

Obviamente, a Gottfried se le plantea un violento dilema moral: el de colaborar o no con el Comandante. Gottfried entiende perfectamente que no puede rechazar el papel de «traductor» (153) que el Comandante le ha ofrecido,

2 Por comodidad, nos referimos así a la(s) página(s) de la obra teatral de Juan Mayorga -Himmelweg (2011c) - donde fueron extraídas las citas. 
que su grupo de judíos no tiene libertad para negarse a interpretar la obra porque en ello les va la vida. Es obvio que ensayar y actuar implica su supervivencia y que negarse a ello supone ser conducidos a la enfermería, es decir, a la cámara de gas, una «solución final» que se ha aplicado a todos los demás judíos de los trenes llegados y por llegar. Finalmente, se decide a «colaborar» para salvar momentáneamente su vida y la de todo el grupo de judíos, a los que «traduce» el proyecto del Comandante y a los que trata de convencer de que actuar es sobrevivir. Porque, según el Comandante, han tenido el privilegio de haber sido «elegidos» por Berlín, e inclusive el propio Comandante se siente orgulloso de que los jerarcas nazis le hayan «elegido» también a él:

Gottfried, hemos recibido instrucciones muy positivas para ustedes. Berlín los ha elegido. También a nosotros, podemos decirlo con orgullo: Berlín nos ha elegido. Tenemos un proyecto que compartir. Berlín quiere echar abajo ciertos prejuicios. Prejuicios acerca de la relación entre nuestros pueblos. (154)

Una vez «elegidos» el Comandante y este grupo de judíos por los jerarcas nazis de Berlín, debe iniciarse un proceso de trabajo que ha de desembocar en la puesta en escena de una obra que está aún por escribir. Y, aunque a lo largo del proceso de ensayos el Comandante se presente como una víctima más de la orden dictada por sus superiores de Berlín - « Mis deseos? ¿Crees que yo tengo deseos, Gershom? Berlín me ha elegido. Igual que a ti. Berlín nos ha elegido» (166)-, en rigor actúa como el director de escena, o mejor, como el dictador de escena, aunque para escribir la obra en «un cuaderno que llamaremos libreto» (156), "para componer un guión» (155) según la Poética de Aristóteles (Brignone 2011: 73-80) y constituir luego la compañía y repartir los distintos papeles, necesita un ayudante de dirección judío, un «traductor» psicológico de su lenguaje, trabajo para el que ha elegido a Gottfried «porque nos hemos fijado en que su gente le respeta» (153).

La primera violencia que el Comandante ejerce contra Gottfried, su traductor judío, es la de confundir su nombre, preludio de su futuro objetivo de anular su identidad:

Comandante - Su nombre es... (Lee en el expediente.) Gerhard Gottfried.

GotTFRIED - Gershom Gottfried.

Comandante - ¿Su nombre no es Gerhard?

GOTTFRIED - Gershom. (153)

Obviamente, al darle a Gottfried el nombre de Gershom, Mayorga está homenajeando explícitamente a Gershom Scholem (1987, 2003 y 2011), fiel amigo de Walter Benjamin, protagonista, por cierto, de la obra en un acto de Juan Mayorga que se titula $J K$, dos letras que significan judío y comunista.

Y, a continuación, el Comandante le explica a Gottfried que todo el campo va a ser el teatro de la representación y que, por ello, se está construyendo la escenografía de este campo «modelo», que va a contar con un colegio, un campo de fútbol y hasta una sinagoga. Una escenografía que trata de reflejar el respeto humano y la tolerancia religiosa que se vive en aquel campo, en donde los judíos 
están obligados a representar la farsa siniestra de la felicidad colectiva, a fingir que gozan de libertad y que son tratados por sus verdugos nazis con la misma dignidad que merece todo ser humano.

\section{Autómatas y marionetas: la destrucción de la dignidad humana}

Ya hemos dicho que la violencia en Himmelweg no es explícita, no es física, porque la violencia explícita es menos eficaz dramatúrgicamente y porque, en rigor, provoca insensibilidad en el lector o en el espectador. La violencia del Comandante nazi no es contra el cuerpo, sino contra el alma. No es una violencia física sino mucho peor, es una violencia moral, psíquica, que implica la amenaza, el chantaje, la coacción, la humillación. Una violencia que el Comandante ejerce sin piedad y sin un ápice de humanidad, sin reparar en medios para conseguir el objetivo final: en este caso, una representación teatral perfecta. Por tanto, este personaje nazi encarna a la perfección la cultura y barbarie benjaminianas:

Después del Holocausto, contraponer cultura a barbarie es una peligrosa ingenuidad. Se puede escuchar la mejor música por la mañana y torturar por la noche. Se puede llorar de emoción ante un cuerpo pintado o esculpido y contemplar con indiferencia el dolor de un ser humano. Una sociedad de lectores, una sociedad que llene los museos, una sociedad que abarrote los teatros, puede aplaudir el genocidio. (Mayorga 1999: 61)

Un Comandante nazi que se muestra orgulloso de su biblioteca mientras firma insensible y rutinariamente penas de muerte -«Echen un vistazo a mi biblioteca; eso es Europa para mí. Echen un vistazo mientras firmo estos expedientes» (148) - y que se jacta, con sumo orgullo y sin tapujos en su monólogo de "Así será el silencio de la paz», de la llamada «Solución Final»: «Antes de juzgarnos, recuerden que nosotros estamos dando solución a un problema que ha atormentado durante siglos a toda Europa. [...] Otros lo habían soñado; nosotros lo hemos hecho» (150-151).

Y para hacer invisible el horror de la «Solución Final», del «Todo es posible» nazi, el Comandante de Himmelweg va a servirse del teatro como medio artístico para enmascarar la realidad trágica que padecen los judíos. Porque el nazismo es una ideología en donde no existen los límites morales, en donde «todo es posible»:

El objetivo inmediato es reagrupar aquí a todos los hebreos de Europa. Pero nuestro objetivo final es mucho más elevado. Nuestro objetivo final es demostrar que todo es posible. Todo es posible. Todo lo que podemos soñar, podemos hacerlo realidad. Aquí, en este mundo. Incluso lo que nunca nos hemos atrevido a imaginar (151).

Obviamente, sin límites morales, todo es posible en este mundo, hasta las formas más extremas de barbarie y violencia:

Todos estos son elementos que se utilizan, desarrollan y cristalizan sobre la base del principio nihilista de que «todo está permitido», que heredaron y dieron por supuesto. Pero allí donde todas estas nuevas formas de dominación asumen su 
estructura auténticamente totalitaria superan este principio, que sigue ligado a los motivos utilitarios y al interés propio de los dominadores y penetran en un terreno que hasta ahora nos resultaba completamente desconocido: el terreno donde «todo es posible» [...] Lo que se rebela contra el sentido común no es el principio nihilista de que «todo está permitido», que se hallaba ya contenido en la concepción utilitaria y decimonónica del sentido común. Lo que el sentido común y la «gente normal» se niegan a creer es que todo sea posible. (Arendt 2006: 592)

Y Arendt concluye estas lúcidas páginas dedicadas a «la dominación total» reafirmándose en su convicción de que los campos de exterminio nazis constituyeron los laboratorios donde se ensayó la destrucción «de lo que nosotros denominamos corrientemente dignidad humana» (2006: 615):

Los campos de concentración son los laboratorios donde se ensayan los cambios en la naturaleza humana [...] Lo que está en juego es la naturaleza humana como tal, y aunque parezca que estos experimentos no lograron modificar al hombre, sino sólo destruirle, creando una sociedad en la que la banalidad nihilista del homo homini lupus es consecuentemente realizada, es preciso tener en cuenta las necesarias limitaciones de una experiencia que requiere un control global para mostrar resultados concluyentes. (Arendt 2006: 615).

El nazismo consiguió realizar ese «Todo es posible» porque es obvio que en demasiadas ocasiones el horror de la realidad supera al de la ficción. Y está claro que el horror de la realidad de los campos de exterminio nazis supera a la imaginación humana, incapaz de representarlo:

No existen paralelos para la vida de los campos de concentración. Su horror nunca puede ser abarcado completamente por la imaginación por la simple razón de que permanecen al margen de la vida y de la muerte. (Arendt 2006: 596)

No olvidemos que la derrota en la Primera Guerra Mundial fue una herida abierta en la sociedad alemana y, en este sentido, Walter Benjamin afirmó en «Teorías del fascismo alemán» -en rigor, una reseña de la colección de ensayos Guerra y guerreros de Ernst Jünger, editada en 1930-, que «la guerra -"la guerra eterna", así como la anterior de la que tanto se habla-, sería la más elevada expresión de la nación alemana» (1999: 50) y que "esta nueva teoría de la guerra, que tiene su origen rabiosamente decadente inscrito en la frente, no es más que una transposición descarada de la tesis de L'Art pour l'Art a la guerra» (1999: 49).

Conviene recordar aquí y ahora el impecable relato, sin un gramo de grasa, que la tortuga Harriet hace de la Shoah en La tortuga de Darwin, estrenada el 6 de febrero de 2008 en el Teatro de la Abadía de Madrid. Un relato tan preciso como conciso, tan conmovedor como estremecedor:

Toma la palabra un hombrecillo. «¿Por qué, si somos los más fuertes, perdimos la guerra? Porque los judíos nos apuñalaron por la espalda». Yo me digo: «La gente recuerda cómo fueron las cosas, payaso; van a hacerte callar y, si sigues contando mentiras, te darán una buena paliza». Qué va, nadie protesta, y cuando el payaso dice «Todo es posible. ¡Todo es posible!», miles, decenas de miles levantan sus manos y gritan como una única garganta «iTodo es posible!». Entonces me doy cuenta de que el payaso es un tipo peligroso. Pero es demasiado tarde, yo 
misma siento que la voz del payaso ha tocado mi corazón y levanto mi patita y sumo mi chillido de tortuga a millones de gargantas entusiasmadas, «Heilhitler!, ¡iHeilhitler!!», es una fuerza incontenible, nunca he sentido tanta energía dentro de mí, «iiiHeilhitler!!!», y en mi corazón animal se levanta una promesa: «Todo es posible». (Mayorga 2015: 208)

Y, tras presenciar en abril de 1937 el bombardeo de Guernica durante la guerra civil española, la tortuga Harriet pasa a relatar su detención y posterior deportación en tren, junto a un grupo de judíos, hasta un campo de exterminio nazi, en donde les hacen subir por una rampa, camino del cielo, hasta la cámara de gas:

Ser tortuga es más peligroso que ser persona, pero ser judío es más peligroso que ser tortuga. Y en una de estas, yendo de vieja, me meten con más gente en un tren de ganado. [...] El tren frena, las compuertas se abren, los separan en dos filas. A los niños, a los viejos, a los débiles, los desnudan, les cortan el pelo y los llevan a duchar. De allí, en carretillas, los llevan a un gran horno. Desde el tren hasta la chimenea, todo funciona como una máquina. Yo lo veo subida a un montón de gafas, porque a la gente le quitan las gafas. Entonces comprendo que se ha cumplido la promesa del payaso: «Todo es posible». (Mayorga 2015: 211-213)

Ya hemos dicho que el teatro funciona aquí como medio artístico para conseguir el engaño a los ojos, la invisibilidad del horror y de la violencia. Para lograr ese objetivo, el dictador de escena obliga a los judíos a la diaria tortura de ensayar y volver a ensayar. Porque esta reiteración de los ensayos es fundamental para que el Comandante consiga convertir al coro de judíos en autómatas a través de un proceso de muñequización que les despoje de su individualidad y humanidad, para transformar a los actores judíos en marionetas sordas a los trenes y ciegas al humo, insensibles en escena al horror de la trágica realidad en la que están inmersos, para convertirlos en cómplices del reino del eufemismo, en donde el Comandante llama siempre «enfermería» a la cámara de gas:

Si hay alguien que ha influido en mi trabajo, es el pensador alemán Walter Benjamin, sobre el que escribí mi tesis doctoral. Algo que creo fundamental en Walter Benjamin y en muchos pensadores judíos es su idea de que el lenguaje es extremadamente poderoso en cuanto que el lenguaje puede iluminar la realidad, hacer visible la realidad o, por el contrario, enmascarar la realidad. En ese sentido, el lenguaje es el mayor instrumento de emancipación y al mismo tiempo el máximo instrumento de violencia. (Gabriele 2009: 167)

En efecto, Mayorga dedicó su tesis doctoral a analizar el pensamiento de Benjamin, tesis que publicó en 2003 con el título de Revolución conservadora y conservación revolucionaria. Política y memoria en Walter Benjamin. Pero, llegados a este punto, nos interesa ahora mismo también un pensamiento de Pascal, porque la primera impresión del Delegado al contemplar a Gottfried, es decir, al «Alcalde Gershom Gottfried» según las palabras con que le es presentado por el Comandante, será la de desconcierto ante la presencia de «un hombre sonriente» (133) que "habla con un tono de voz extraño» (133), que "habla como un autómata» (135), mientras que el coro de judíos le parece formado por 
hombres y mujeres que «se mueven con torpeza, con inseguridad» (135), como si fueran malos actores de una ficticia representación teatral. Pero, ¿por qué sonríe Gottfried, es decir, el personaje del Alcalde del campo, al Delegado? La respuesta, en labios del Comandante, nos la proporciona Pascal:

Pensamiento doscientos cincuenta y dos: «Somos autómatas tanto como espíritus». Más adelante, dice: «Es preciso convencer a nuestras dos partes: al espíritu, por medio de razones; y al autómata, por medio de la costumbre». ¿Lo entiende usted, Gottfried? Lo que viene a decir Pascal es que, si rezas, acabas creyendo. Dicho de otro modo: sonríe y acabarás siendo feliz. Los actores conocen esa sabiduría. ¿Tiene usted alguna experiencia en el teatro? (154-155)

Naturalmente, la respuesta de Gottfried, como la de la mayoría de actores del reparto judío - a excepción de la actriz pelirroja, una profesional del teatro que se niega a interpretar su personaje en esta farsa-, es negativa y por eso el Comandante insta, les ordena en los ensayos que sonrían y que vuelvan a sonreír, que repitan y repitan «la costumbre» de sonreír, que las personas se transformen en escena en personajes, que acierten a interpretar la farsa de la felicidad colectiva. Y, naturalmente, en aquel contexto trágico, al coro de judíos les cuesta sonreír, es decir, les cuesta convertirse en actores, en autómatas ciegos ante su trágica realidad: «Y, por favor, que sonrían un poco. A tu gente le cuesta tanto sonreír...» (Mayorgac 2011c: 165).

El objetivo de los reiterados ensayos es, por tanto, «acostumbrar» a los judíos a sonreír, transformar a unos judíos lúcidos de la tragedia que están viviendo en aquel campo de exterminio nazi en actores que sonrían en escena, lo cual es una forma de extrema violencia impuesta por el dictador de escena a sus muñecos, unos cadáveres vivos a los que domina totalmente, a los que somete en vida a la tortura de su muerte moral, a los que quiere despojar cruelmente de su dignidad humana.

La diaria y reiterada repetición de los ensayos, al igual que la instrucción diaria en el ejército, tiene un objetivo muy claro: educar al soldado, conseguir su obediencia automática, su disciplina. Arendt nos recuerda que «Himmler prohibió explícitamente en los campos la propaganda de cualquier tipo. "La educación consiste en disciplina, jamás en tipo alguno de instrucción sobre una base ideológica"» (2006: 606, nota 151). Y, una vez disciplinado, el interno en un campo, anulada su individualidad, se convierte en un autómata. Así, el actor judío en Himmelweg ha de llegar a ser una simple marioneta a las órdenes del Comandante nazi:

Sólo quedan entonces fantasmales marionetas con rostro humano que se comportan todas como el perro de los experimentos de Pavlov, que reaccionan todos con perfecta seguridad incluso cuando se dirigen hacia su propia muerte y que no hacen más que reaccionar. Éste es el verdadero triunfo del sistema. (Arendt 2006: 611)

Y en este proceso de marionetización, de conversión del interno en autómata, Arendt cita de nuevo a David Rousset, autor de Les Jours de notre mort (1947): 
El triunfo de las SS exige que la víctima torturada se deje llevar hasta la trampa sin protestar, que renuncie a sí misma y se abandone hasta el punto de dejar de afirmar su identidad. [...] Nada hay más terrible que estas procesiones de seres humanos caminando como muñecos hacia su muerte. (Arendt 2006: 611 y 2015: 26-27)

Arendt (2006: 612) afirma que «sin los campos de concentración, [...] un estado totalitario [...] no puede mantener a todo un pueblo en la completa apatía». Y, en este sentido, los campos constituyen el laboratorio perfecto para lograr la dominación total del hombre, su conversión en un autómata sumiso y disciplinado, en una marioneta a modo de nuevo perro de Pavlov:

El perro de Pavlov, espécimen humano reducido a sus reacciones más elementales, el haz de reacciones que puede ser siempre liquidado y sustituido por otro haz de reacciones que se comporten exactamente de la misma manera, es el ciudadano «modelo» de un estado totalitario, y semejante ciudadano sólo puede ser producido imperfectamente fuera de los campos. (Arendt 2006: 611)

Pero, lógicamente, el proceso de ensayos es lento y difícil, muy insatisfactorio para el Comandante nazi, tanto por la inexperiencia escénica de la mayoría de los actores judíos como porque siguen escuchando trenes a las seis en punto de cada mañana y siguen viendo el humo de la "enfermería», es decir, porque tienen conciencia de la realidad trágica y, por tanto, no entienden el sentido de esa representación teatral que ensayan una y otra vez todos los días. Gottfried le «traduce» al Comandante el sentir colectivo de la improvisada compañía teatral cuando le dice que «la gente necesita saber qué puede esperar» tras la representación, a lo que el Comandante le responde:

¿Qué pueden esperar? ¿Quieren saber qué pueden esperar? Todos queremos saber qué podemos esperar. Pero la vida es incertidumbre. [...] ¿Necesitan un sentido? Déles un sentido. Vaya y hábleles. Pero, al elegir sus palabras, recuerde: «Mientras estemos aquí, no estamos en ese tren». (162)

La irritación del Comandante, un apasionado del teatro, va en aumento a medida que contempla la escasa calidad artística de los ensayos y llega a plantearle a Gottfried un ultimátum que significa la interrupción del proyecto teatral: «Voy a enviar un telegrama a Berlín. "Misión imposible. Stop. Esperamos nueva orden"» (158). Y Gottfried, consciente de que esa suspensión significaría la muerte inmediata de todos los judíos, consigue convencer al Comandante de que tenga paciencia porque, con tiempo y esfuerzo, los resultados artísticos de la compañía van a mejorar y porque él mismo va a esforzarse en su monólogo del reloj: «Fue construido hacia el año mil quinientos dos por el maestro Peter Henlein, de Nuremberg, el famoso fabricante de juguetes automáticos» (160). En efecto, el desarrollo en tres actos - «Primer acto: la ciudad; segundo acto: el bosque; tercer acto: la estación» (156)- de la acción dramática de esta farsa exige que, tras la comida con la familia de Gottfried, bendecida «al modo judío» (134), el Comandante invite al Delegado a visitar libremente el campo, a dar un plácido paseo a través del bosque, bordeando el río, hasta llegar ante el reloj de la estación, que marca siempre las seis en punto. Éste es el espacio 
escénico elegido por el Comandante para que Gottfried interprete su monólogo, espléndidamente analizado por Enrico di Pastena (2010 y 2012). Y desde allí, «al otro lado de las vías», el Delegado va a ver dos rampas, a una de las cuales, «una rampa de subida, más suave y más larga, que acaba en una especie de hangar», el Comandante la llamará «Camino del cielo», un lugar privilegiado para contemplar la escena de la plaza:

DELEgADo - «Desde allí se ve toda la ciudad», dice el comandante, y me invita a comprobarlo. En efecto, desde lo alto de la rampa se ve la ciudad entera. En la plaza, todo vuelve a moverse como un juguete al que se ha dado cuerda: los niños de los columpios, los viejos paseando al sol, el vendedor de globos... (137)

Pero el actor que interpreta el personaje del vendedor de globos es distinto al inicial, porque el Comandante, convencido de que el fin justifica los medios, se sirve de la violencia y no duda en eliminar, de una manera fría, sin una pizca de compasión humana, a todos los malos actores:

Comandante - ¿Los excedentes? [...] Lo mejor será trasladarlos a la enfermería. Sí, definitivamente, será la mejor solución para ellos: la enfermería. (165)

Y entre esos malos actores está por ejemplo Tadeusz, el profesor universitario de Historia, insomne en las madrugadas porque ha enloquecido en el campo y se levanta con frecuencia a comprobar que las ventanas están bien cerradas, una muestra de «humor judío» según el Comandante, totalmente insensible al dolor humano:

Comandante - Ah, se me olvidaba: el vendedor de globos. Definitivamente, no sirve. Se va a la izquierda cuando se tiene que ir a la derecha. Ese hombre no sabe distinguir entre la derecha y la izquierda. [...] En la enfermería le darán algo para que pueda dormir. (160)

Y aunque los ensayos van mejorando progresivamente, la obsesión del Comandante es conseguir que la escena de la plaza, la más difícil por la complejidad de conjuntar a un coro de judíos formado por más de cien personas, resulte artísticamente convincente.

\section{Violencia del verdugo y resignación y pasividad de las víctimas}

Hay un tema que, frente a la sutil, inhumana y permanente violencia que ejerce el Comandante nazi en tanto dictador de escena, me interesa especialmente resaltar en Himmelweg y es el de la ausencia de una respuesta violenta contra él por parte de los judíos.

Arendt afirma que «la destrucción de los derechos del hombre, la muerte en el hombre de la persona jurídica, es un prerrequisito para dominarle enteramente» (2006: 605). Y añade a continuación que «el siguiente paso decisivo en la preparación de los cadáveres vivientes es el asesinato de la persona moral en el hombre» (2006: 606). Así, la protesta carece de sentido en esas circunstancias y ello explica la pasividad y la resignación con que actúan los internos: 
¿Cuántas personas siguen creyendo que una protesta ha tenido alguna vez importancia histórica? Este escepticismo es la auténtica obra maestra de las SS, su gran realización. Han corrompido toda solidaridad humana. Aquí la noche ha caído sobre el futuro. [...] Para tener éxito, un gesto debe poseer un significado social. Aquí somos centenares de miles, todos viviendo en una absoluta soledad. Por eso es por lo que estamos sometidos a todo lo que pueda suceder. (Arendt 2006: 606).

En rigor, a excepción de la actriz pelirroja y de Rebeca, una pasividad no exenta de angustiada lucidez y de patética esperanza caracteriza la actitud colectiva de este grupo de judíos resignados y sumisos. Ello explica, por ejemplo, que el actor que interpreta el personaje de Él en la escena segunda, a diferencia de la actriz profesional pelirroja, no vea el humo, no quiera ver el humo, se niegue como cadáver vivo a ver la realidad, a olvidarla por el terror, por la extrema violencia de la situación que padece:

Tras el asesinato de la persona moral y el aniquilamiento de la persona jurídica, la destrucción de la individualidad casi siempre tiene éxito. Concebiblemente, pueden encontrarse algunas leyes de la psicología de masas para explicar por qué millones de seres humanos se dejaron llevar sin resistencia a las cámaras de gas, aunque estas leyes sólo explicarían la destrucción de la individualidad [...], porque destruir la individualidad es destruir la espontaneidad. (Arendt 2006: 610)

Sin embargo, Gottfried se atreve a preguntar al Comandante nazi por las consecuencias de una posible negativa a representar la obra ante el Delegado: "¿Y si nos negamos a hacerlo? [...] O él llega y la gente no se comporta como usted quiere. [...] O le decimos la verdad» (166).

Gottfried mantiene una actitud de «resistencia prudente» (Floeck 2012) ante el Comandante y trata siempre de justificar la falta de concentración y las insuficiencias artísticas de sus compañeros judíos. Una actitud de «resistencia prudente» que, según Floeck, se expresa ante todo por sus clamorosos silencios, que funcionan muchas veces como respuesta a la violencia del Comandante y como expresión de su patética impotencia:

Su resistencia más impresionante frente a su opresor no se expresa, sin embargo, en palabras, sino, más bien, en el rechazo de las mismas, en su silencio obstinado. [...] La palabra «silencio» es la expresión más utilizada en las acotaciones de esta parte, un silencio mudo y elocuente a la vez, como un arma impotente en la lucha contra un enemigo desigual contra el que no sirve ningún arma. (Floeck 2012)

Contra esta actitud de «resistencia prudente» el Comandante le recuerda que es su «traductor» y no el abogado defensor del coro judío. Sin embargo, esa pasividad y resignación de Gottfried, sus silencios sonoros, únicamente se quiebran cuando pronuncia ante el Delegado la «morcilla lírica» del barco y el capitán: «Somos un barco al que las minas no dejan entrar a puerto. El capitán conserva la paciencia, mientras aguarda una señal verdadera» (169). Unas palabras cuyo sentido confiesa el Comandante no haber entendido: «El barco, ¿qué representa? ¿Qué significa el puerto? ¿Quién demonios es el capitán? ¿Tú?, ¿yo?, ¿él?» (169). Porque éste únicamente pierde su impasibilidad en dos 
momentos que significan una transgresión de la disciplina textual de la obra: al escuchar esa «morcilla lírica» de Gottfried y cuando la niña Rebeca, al final de la representación, cambia el «Sé amable, Walter, saluda a este señor» y pronuncia una variante -«Escapa, Rebeca, que viene el alemán» (169)- que expresa el terror de la víctima inocente ante su verdugo nazi.

Sin embargo, el Comandante no se priva de humillar a Gottfried cuando le confiesa, con su habitual crueldad, que su sumisa pasividad y la del resto de judíos le ha decepcionado: «Por un momento, pensé que intentaríais algo. ¿Me creerás si te digo que, por un momento, deseé que lo hicieseis? [...] Y, cuando empezaste con lo de los barcos, pensé: "Por fin. Por fin Gershom va a hacerlo"» (169).

\section{La escena de la plaza}

La violencia del Comandante sobre Gottfried va a alcanzar un momento de extraordinaria intensidad con motivo de la escena de la plaza, una escena clave para el engaño al Delegado: «En esa escena tiene que percibirse, ¿cómo decirlo?, el espíritu de la comunidad. Habrá que coordinar las actitudes, los gestos, las miradas...» (157). Una escena que, según el Comandante, no acaba de funcionar por un exceso de gente: «Demasiada gente. Te lo dije desde el principio» (165). Por ello, finalmente va a obligarle a descartar a los actores «excedentes», es decir, a ser cómplice suyo en el asesinato de esos judíos que, eliminados de la representación escénica, serán automáticamente condenados a la cámara de gas: «Cien. Cuida las proporciones, tiene que haber de todo: hombres y mujeres, niños y viejos...» (165).

Así, mientras el Comandante lee uno de los libros de su selecta biblioteca -cultura y barbarie benjaminianas-, Gottfried renuncia en un primer momento a separar ningún expediente, pero finalmente se decide a hacerlo -aunque tiene la dignidad moral de excluirse él mismo- cuando comprende la inutilidad de su insumisión: «Silencio. Gottfried empieza a apartar expedientes del grupo» (166).

De este modo, desde el momento en que Gottfried acepta reducir la escena de la plaza a un coro compuesto únicamente por cien actores judíos, el Comandante nazi ha conseguido su complicidad criminal, su muerte moral. Hannah Arendt, al referirse a la exclusión en el juicio contra Adolf Eichmann del libro de H. G. Adler sobre Theresienstadt, 1941-1945, publicado en 1955, explica que:

[...] el libro describe detalladamente el modo en que el Consejo Judío de Theresienstadt formaba las «listas de transporte», después de que las SS les hubieran dado algunas directrices, concretando el número de judíos que debían ser transportados, su edad, sexo, profesión y país de origen. La postura de la acusación hubiera quedado debilitada si se hubiera visto obligada a reconocer que la determinación de los individuos que debían ser enviados a la muerte era, salvo escasas excepciones, tarea de la administración judía (Arendt 2015: 176-177).

Así, «gracias a ellos, judíos que participan en el exterminio, se carga sobre las víctimas el peso de la culpa» (García Barrientos 2011: 60-61). Gottfried se ha visto obligado a mancharse las manos de sangre y este hecho supone la victoria 
definitiva del verdugo sobre su víctima, su dominación total al haber logrado esa complicidad con los asesinatos de los judíos «excedentes»:

La alternativa ya no se plantea entre el bien y el mal, sino entre el homicidio y el homicidio. ¿Quién podría resolver el problema moral de la madre griega a quien los nazis permitieron decidir cuál de sus tres hijos tendría que ser muerto? [...] Los hombres de las SS implicaron en sus crímenes a los internos en los campos de concentración -delincuentes, políticos y judíos-, haciéndoles responsables de gran parte de la administración, enfrentándose de esa manera con el desesperanzador dilema de si enviar a sus amigos a la muerte o si ayudar a matar a otros hombres que resultaban serles extraños y, en cualquier caso, obligándoles a comportarse como asesinos. El hecho no es sólo que el odio fuera desviado de quienes realmente eran culpables (los Kapos eran más odiados que los hombres de las SS), sino que se hallara constantemente enturbiada la línea divisoria entre el perseguidor y el perseguido, entre el asesino y su víctima. (Arendt 2006: 607-608).

\section{Medios y fines: el cinismo como arma}

En la medida en que la violencia se sustenta en una permanente amenaza de muerte, el medio de que se sirve el Comandante para conseguir su fin nos obliga a plantearnos también el problema de los medios y de los fines:

La verdadera sustancia de la acción violenta es regida por la categoría medios-fin cuya principal característica, aplicada a los asuntos humanos, ha sido siempre la del que el fin está siempre en peligro de verse superado por los medios a los que justifica y que son necesarios para alcanzarlo. (Arendt 2005: 10)

Por su parte, Walter Benjamin (1999: 23), en su ensayo Para una crítica de la violencia, sostiene que para resolver «la cuestión de si la violencia es en general ética como medio para alcanzar un fin», sería necesaria «una distinción dentro de la esfera de los medios, independientemente de los fines que sirven». El fin del Comandante nazi ya hemos dicho que consiste en engañar al Delegado y ese objetivo se cumple en la medida en que éste acaba por redactar un informe favorable. Y el medio para lograr ese objetivo es el teatro, la puesta en escena de una comedia rosa, de una farsa siniestra que va a conseguir enmascarar la realidad trágica de los judíos en el campo de exterminio, una representación teatral que será perfecta no únicamente por su calidad artística sino, ante todo, porque acierte a lograr el abyecto fin que se propone.

Obviamente, el Comandante no es un cínico, pero no tiene ningún reparo ni ninguna mala conciencia en utilizar la mentira y el cinismo en algunas ocasiones como medios para conseguir el fin que le obsesiona: el de una representación teatral perfecta que logre engañar al Delegado. Así, las mentiras y el cinismo, medios legítimos para conseguir su fin, son armas del Comandante contra Gottfried, otras formas de violencia contra los judíos. Y como prueba de su cinismo y de sus mentiras baste recordar que, por ejemplo, finge ignorar la existencia de trenes que llegan cada madrugada: 
GotTFRIED - Esta noche me pareció oír un tren.

Comandante- ¿Un tren? No tengo noticia de que haya llegado ningún tren. ¿No sería en sueños? [...] Si hubiese llegado un tren, yo tendría que saberlo. Preguntaré. ¿Dónde estábamos? La composición. (156)

El Comandante nazi no sólo responde con una mentira y con un cinismo calculado («Si hubiese llegado un tren, yo tendría que saberlo. Preguntaré»), sino que finge avergonzarse del maltrato a los judíos por parte de algunos soldados nazis a sus órdenes, según él unos incontrolados a los que promete castigar:

Lamentamos lo sucedido, nos produce vergüenza. Sabemos que fueron tratados como animales. Por desgracia, no podemos controlar a todos los que visten este uniforme. Honrados padres de familia se convierten en bestias en cuanto se ven con nuestro uniforme. Le garantizo que los responsables serán tratados como corresponde. (153-154)

Pero el colmo de este cinismo moral alcanza su límite cuando, en su monólogo de «Así será el silencio de la paz»-cuyos destinatarios somos nosotros, lectores o espectadores de Himmelweg-, el Comandante diferencia claramente entre dos mundos, el de «ellos» y el de «nosotros». Y, con la astucia del zorro, trata de establecer una relación de complicidad con nosotros: «Ellos son muy celosos de sus cosas. No les gusta que unos extraños merodeen en sus vidas. Ellos no son como nosotros, como ustedes y yo. ¿Otro café?» (149). Para añadir a continuación, a modo de guinda de su pastel cínico, las miserables palabras siguientes:

Y, una vez más, permítanme recomendarles prudencia. No confíen en lo que vean. Generación tras generación, esa gente ha sido educada en el disimulo. Hace siglos, esa gente descubrió que no hay nada más rentable que pasar por víctima. Pero ustedes no se van a dejar engañar. (150)

El Comandante, un personaje que encarna la despiadada violencia y barbarie del nazismo, pero que no puede ser interpretado en modo alguno como un payaso histriónico o un fanático farsesco sino todo lo contrario, como un encantador de serpientes, astuto, mentiroso, cruel, inteligente y cínico -«Díganme algo en su idioma, por favor. Una palabra: "Paz"» (148)-, para quien todo vale si sirve para lograr el fin porque todo es posible en un mundo sin límites morales, nos explica el mundo al revés, un relato en el que la víctima se convierte en verdugo y viceversa, un nuevo intento de engañarnos a nosotros hoy, como consiguió en el pasado engañar al Delegado:

Permítanme un consejo: nada más salir de aquí, empiecen a olvidar. Y así, cuando lleguen a sus casas, podrán tomar papel y pluma y escribir un bonito informe. Hoy como entonces. (151)

La cobardía de aquel Delegado le condujo a escribir un informe favorable a los nazis y Mayorga nos plantea ahora a nosotros, nuevos Delegados, la responsabilidad de escribir un nuevo informe, es decir, la responsabilidad de plantearnos preguntas como qué habríamos hecho nosotros si hubiéramos estado en la situación del Delegado o qué haríamos en situaciones similares hoy 
en día, es decir, si nosotros, como el Delegado de la Cruz Roja, vamos a volver a cerrar los ojos por cobardía ante nuestra realidad actual o vamos a tener el coraje de abrirlos a la tragedia que la representación teatral enmascara y que la obra de Mayorga quiere y consigue visibilizar. Dicho de otra manera, el dramaturgo nos plantea si vamos a tener el coraje de interpretar la «muy intensa» (138) mirada de Gottfried -«Hoy sé por qué me miraba así. Me miraba como pensando: “Ahí va un hombre vivo"» (138)-, o sus palabras líricas sobre el barco y el capitán; si vamos a atrevernos a preguntarle a Gottfried o a «la niña que jugaba en el río con un muñeco» (138) y que no ha dicho el texto ensayado de «Sé amable, Walter, saluda a este señor» (171) sino «escapa, Rebeca, que viene el alemán» (169).

En definitiva, si vamos a tener el coraje de abrir «la puerta del hangar» que, tras ascender la rampa «camino del cielo», da paso a la «enfermería» - «Todavía recuerdo el frío en los dedos al tocarla» (138), afirmará el Delegado-; si vamos a tener el coraje de abrir la puerta que da acceso a la cámara de gas, es decir, si nos vamos a atrever a abrir los ojos ante las mentiras y los engaños de los nuevos Comandantes en nuestro mundo actual.

\section{La melancolía del actor, sentencia de muerte}

La representación teatral ha sido casi perfecta, sólo empañada por la «morcilla» de la niña Rebeca antes señalada, que finalmente, en lo que constituye un inteligente efecto de patetismo trágico por parte de Mayorga, se nos revela como la hija de Gottfried. Y esta anagnórisis final, inesperada aunque anunciada -«He estado leyendo su expediente. Tiene una mujer, una hija, una vida» (160)impregna de una conmovedora ternura su obstinación ante el Comandante de que el inicial personaje de un niño - ¿¿Por qué una niña? Yo había pensado en un niño» (157) - sea interpretado por una niña: «Por su voz. Le va a gustar su voZ» (157).

Así, tras haber conseguido el éxito con la puesta en escena de esta farsa siniestra, el Comandante nazi va a realizar ante Gottfried una reflexión metateatral de una extrema violencia y crueldad. El Comandante, en su reflexión final sobre «la melancolía del actor», que funciona dramáticamente como una fría y despiadada sentencia de muerte, diferencia claramente entre persona y personaje y, acabada la representación, a la muerte del personaje en escena ha de suceder inexorablemente la muerte del actor en la cámara de gas:

Comandante- ¿Habías oído hablar de la melancolía del actor? Ahora sabes de qué se trata. Cae el telón y, de pronto, todo ese mundo de palabras y de gestos, todo ese mundo se desvanece. Cae el telón y al actor no le queda nada.

Silencio.

[...]

Cae el telón y el actor vuelve a la vida. Y no siempre la vida es agradable. Tú lo sabes tan bien como yo, no siempre la vida es dulce. No vivimos en el paraíso, Gerhard. Quizá algún día. Pero todavía no. (167) 
Es el fin de la esperanza para todo el reparto judío, el fin de la violencia padecida por el «traductor» Gottfried en su relación con los demás judíos del reparto, a los que ha animado una y otra vez durante todo el proceso de ensayos a mejorar su interpretación -«Sé que podéis hacerlo» (171)- a concentrarse en la escena -«Concentráos en lo que estáis haciendo. Sé que es difícil, por causa de los trenes. Procurad no oírlos. Concentráos en las palabras y en los gestos» (171)-, a seguir esperando: «Tenemos que seguir esperando un poco más» (171). Una relación especialmente entrañable por su patetismo trágico con su hija Rebeca, a la que le anima a interpretar su personaje con mentiras piadosas que la niña cree con conmovedora e ingenua inocencia:

Si lo haces bien, volveremos a ver a mamá. Ella va a venir en uno de esos trenes. Si hacemos lo que ellos nos piden. No vamos a perder la paciencia, ¿verdad, Rebeca? Lo haremos tantas veces como sea necesario hasta que mamá vuelva, ¿verdad que lo vamos a hacer tantas veces como haga falta? Si tú puedes, yo también podré. Y si yo no pudiese, si yo perdiese la paciencia, tú no la perderías. Tú vas a seguir hasta el final. Por mamá. Por mamá y por mí, si yo pierdo la paciencia. «Sé amable, Walter, saluda a este señor». (171-172)

En definitiva, de la cruel reflexión metateatral sobre la melancolía del actor que realiza el Comandante nazi de Himmelweg, ejemplo de la «banalidad del mal», cabe decir lo mismo que Hannah Arendt escribió sobre Adolf Eichmann al comentar las últimas palabras que pronunció en el juicio contra él que tuvo lugar en Jerusalén («¡Viva Alemania! ¡Viva Argentina! ¡Viva Austria! Nunca las olvidaré»):

Fue como si en aquellos últimos minutos resumiera la lección que su larga carrera de maldad nos ha enseñado, la lección de la terrible banalidad del mal, ante la que las palabras y el pensamiento se sienten impotentes. (Arendt 2015: 368)

\section{Bibliografía}

AAVV, 1968, Theresienstadt, Viena, Europa Verlag.

Arendt H., 2005, Sobre la violencia, Guillermo Solana (trad.), Madrid, Alianza Editorial.

Arendt H., 2006, Los orígenes del totalitarismo, Guillermo Solana (trad.), Madrid, Alianza Editorial.

Arendt H., 2015, Eichmann en Jerusalén, Carlos Ribalta (trad.), Barcelona, Penguin Ramdom House.

Aznar Soler M., 2011a, «Memoria, metateatro y mentira en Himmelweg, de Juan

Mayorga», in: Mayorga J., Himmelweg, Manuel Aznar Soler (ed.), Ciudad Real, Ñaque Editorial, p. 15-112.

Aznar Soler, 2011b, «Entrevista a Juan Mayorga sobre Himmelweg», in: M. Aznar

Soler (ed.), Mayorga J., Himmelweg, Ciudad Real, Naque Editorial, p. 267-276. 
Bartolomé V., 2011, «El teatro dialogando consigo mismo. La metateatralidad en Himmelweg y Cartas de amor a Stalin», in: Mabel Brizuela (ed.), Un espejo que despliega. El teatro de Juan Mayorga, Córdoba, Universidad Nacional de Córdoba, Facultad de Filosofía y Humanidades, p. 83-98.

Benjamin W., 1999, Para una crítica de la violencia y otros ensayos, Eduardo Subirats (ed.), Roberto Blatt (trad.), Madrid, Taurus.

Brigone G., 2011, «Huellas de la Poética de Aristóteles», in: Mabel Brizuela, Un espejo que despliega. El teatro de Juan Mayorga, Córdoba, Universidad Nacional de Córdoba, Facultad de Filosofía y Humanidades, p. 73-80.

Brizuela M., 2011, «Una cartografía teatral», in: Mabel Brizuel (ed.), Un espejo que despliega. El teatro de Juan Mayorga, Córdoba, Universidad Nacional de Córdoba, Facultad de Filosofía y Humanidades, p. 9-24.

Di Pastena E., 2010, «El reloj y la canción: la dimensión metatextual en Himmelweg», Annali dell'Istituto Orientale di Napoli -sezione Romanza, LII, 1-2 (enero-julio), p. 29-57.

Di Pastena E., 2012, «La forma della memoria. La Shoah nel teatro di Juan Mayorga», in: AAVV, Scene di vita. L'impegno civile nel teatro spagnolo contemporáneo, Silvia Monti y Paola Bellomi (eds.), Alessandria, Edizioni dell'Orso, p. 23-50.

Floeck W., 2012, «La shoah en la era de la globalización. Juan Mayorga y el teatro de la memoria», Don Galán. Revista de investigación teatral, 2, http://teatro.es/ contenidos/don Galan/donGalanNum2/sumario.php [Consulta: 19/12/2106].

Gabriel J.-P., 2009, «Entrevista con Juan Mayorga», in: Los dramaturgos hablan. Entrevistas con autores del teatro español contemporáneo, Oviedo, KRK Ediciones, p. 175-188. Esta entrevista se publicó anteriormente en la revista Anales de la Literatura Española Contemporánea, 25.3, 2000, p. 1095-1103.

García Barrientos J.L., 2011, «El Holocausto en el teatro de Juan Mayorga», in: Mabel Brizuela (ed.), Un espejo que despliega. El teatro de Juan Mayorga, Córdoba, Universidad Nacional de Córdoba, Facultad de Filosofía y Humanidades, p. 39-63.

Hofmann M., 2011, Historia de la literatura de la Shoah, Jimena Aguilar Prieto (trad.), Barcelona, Anthropos.

Mate R., 2003a, Por los campos de exterminio, Barcelona, Anthropos.

Mate R., 2003b, Memoria de Auschwitz. Actualidad moral y politica, Madrid, Editorial Trotta.

Mate R., 2006, Medianoche en la historia, Comentarios a las tesis de Walter Benjamin «Sobre el concepto de historia», Madrid, Editorial Trotta.

Mayorga J., 1999, «Cultura global y barbarie global», Primer Acto, 280 (septiembreoctubre), p. 60-64.

Mayorga J., 2003, Revolución conservadora y conservación revolucionaria. Política $y$ memoria en Walter Benjamin, Barcelona, Anthropos.

Mayorga J., 2007, «La representación teatral del Holocausto», Raíces, 73, p. 27-30. 
Mayorga J., 2011a, «El teatro piensa; el teatro da que pensar», Primer Acto, 337, p. 16.

Mayorga J., 2011b, «Hacia una justicia general anamnética», Isegoría. Revista de Filosofía Moral y Política, 45 (julio-diciembre), p. 715-718.

Mayorga J., 2011c, Himmelweg, Manuel Aznar Soler (ed.), Ciudad Real, Naque Editora.

Mayorga J., 2015, Hamelin. La tortuga de Darwin, Emilio Peral Vega (ed.), Madrid, Cátedra.

Mayorga J., 2016a, Cartas de amor a Stalin. La paz perpetua, Francisco Gutiérrez Carbajo (ed.), Barcelona, Clásicos Castalia.

Mayorga J., 2016b, Elipses. Ensayos 1990-2016, Segovia, La uÑa RoTa.

Scholem G., 1987, Walter Benjamin. Historia de una amistad, J. F. Yvars y Vicente Jarque (trad.), Barcelona, Ediciones Península.

Scholem G., 2003, Walter Benjamin y su ángel. Catorce ensayos y artículos, Rolf Tiedemann (ed.), Ricardo Ibarlucía y Laura Carugati (trads.), Buenos Aires, Fondo de Cultura Económica.

Scholem G. y Benjamin W., 2011, Correspondencia 1933-1940, Gershom Scholem, Rafael Lupiani (eds.), Madrid, Editorial Trotta.

Traverzo E., 2001, La historia desgarrada. Ensayo sobre Auschwitz y los intelectuales, David Chiner (trad.), Barcelona, Herder.

Traverzo E., 2002, El totalitarisme. Història d'un debat, Jordi Muñoz Mendoza (trad.), Valencia, Universitat de València. 